\title{
EVALUACIÓN DE LA CALIDAD DE BIOL DE SEGUNDA GENERACIÓN DE ESTIÉRCOL DE OVINO PRODUCIDO A TRAVÉS DE BIODIGESTORES
}

\author{
QUALITY ASSESSMENT OF LIQUID ORGANIC FERTILIZER PRODUCED FROM SHEEP \\ MANURE USING ANAEROBIC REACTORS
}

${ }^{1}$ Alicia Medina V., ${ }^{2}$ Lawrence Quipuzco U. y ${ }^{2}$ Juan Juscamaita M.

\begin{abstract}
Resumen
La presente investigación tuvo como objetivo la evaluación de la calidad de dos abonos orgánicos líquidos producidos a partir de estiércol de ovino, mediante dos procesos consecutivos - la digestión anaerobia en biodigestores (Biol I-G) y la fermentación homoláctica sobre el biol obtenido (Biol II-G) - simples y poco costosos, con el fin de identificar alternativas ante el indiscriminado uso de fertilizantes químicos en la agricultura. Por ello, los bioles fueron sometidos a un análisis de parámetros físico-químicos como $\mathrm{pH}$, conductividad eléctrica, concentración de materia orgánica, $\mathrm{C}$, $\mathrm{N}, \mathrm{P}, \mathrm{K}, \mathrm{Ca}, \mathrm{Mg}, \mathrm{Na}$, metales pesados $(\mathrm{Pb}, \mathrm{Cd}, \mathrm{Cr})$ y microbiológicos como cantidad de coliformes totales, coliformes fecales, Staphylococcus sp. y Salmonella sp. Además, se evaluaron los efectos en la germinación y crecimiento de semillas de lechuga en un ensayo de toxicidad Aguda. Los resultados de laboratorio evidenciaron que el Biol II-G alcanzó valores de $\mathrm{pH}$ alrededor de 3.5, un nivel mucho más ácido con respecto al que presentó el Biol I-G (entre 6.87.8). Las concentraciones de nutrientes se incrementaron considerablemente al finalizar el proceso de producción del Biol II-G, muchos de los elementos hasta quintuplicaron sus valores. De igual manera, los metales pesados aumentaron sus concentraciones, sin embargo no sobrepasaron los límites establecidos en la normativa internacional. La carga patógena se redujo totalmente al finalizar el segundo tratamiento, es decir se puede considerar al Biol II-G como un producto inocuo para su aplicación como fertilizante orgánico.Finalmente, el ensayo de fitotoxicidad demostró que las concentraciones muy altas de los bioles ( $100 \%$ y $10 \%$ con Indice de Germinación $<80 \%)$ inhiben la germinación de las semillas de lechuga y limitan el crecimiento de la radícula. Mientras que las concentraciones del $1 \%$ y $0.01 \%$ se acercan a las dosis óptimas en la utilización del Biol de I-G y Biol II-G, respectivamente.
\end{abstract}

Palabras claves: Digestión anaeróbica, fermentación homoláctica, biodigestor, biol.

\begin{abstract}
The aim of this study was the quality assessment of two liquid organic fertilizers produced from sheep manure, through two consecutive biological processes - anaerobic digestion in biogas reactors (Biol I - $\mathrm{G}$ ) and homolactic fermentation on that first product (Biol II - G) - simple and inexpensive methods, for identifying alternatives to the indiscriminate use of chemical fertilizers in agriculture.Therefore, the liquid organic fertilizers were subjected to an physicochemical and microbiological analysis including parameters such as $\mathrm{pH}$, electric conductivity, organic material concentration, $\mathrm{C}, \mathrm{N}, \mathrm{P}, \mathrm{K}, \mathrm{Ca}, \mathrm{Mg}, \mathrm{Na}$, heavy metals ( $\mathrm{Pb}, \mathrm{Cd}, \mathrm{Cr}$ ), amount of total coliforms, fecal coliforms, Staphylococcus sp. and Salmonella sp. In addition, we evaluated the effects on germination and growth of lettuce seeds through a Phytotoxicity Test. The laboratory results showed that the Biol II-G pH reached about 3.5 units, more acid than Biol IG (which value was between 6.8-7.8). Nutrient concentrations increased significantly at the end of the Biol II-G production process, many of the elements increased to five times their values. Similarly, heavy metals increased their concentrations; however these did not exceed the limits established by international standards. Pathogen load completely dropped at the end of the second treatment, so we can consider Biol II -G as a safe product for use as organic fertilizer.

Finally, the Phytotoxicity Test showed that very high concentrations (100\% and $10 \%$ with Germination Index $<80 \%)$ inhibited the germination and the growth of the radicle and hypocotyl of lettuce seeds. Meanwhile, the concentrations of $1 \%$ and $0.01 \%$ are close to the optimal dosage in the use of Biol I-G and Biol II -G, respectively.
\end{abstract}

Key words: Anaerobic digestion, homolactic fermentation, bioreactor, organic liquid fertilizer. 


\section{Introducción}

Actualmente, el uso indiscriminado de fertilizantes sintéticos, no sólo ha dejado atrás la utilización del estiércol en la agricultura convencional, sino que además, viene amenazando la salud humana, la calidad del agua, del suelo y del aire. En ese sentido, resulta evidente la necesidad de investigar y analizar tratamientos simples, rápidos y poco costosos - como las alternativas que se proponen en el presente estudio-mediante los cuales sea viable abordar este problema de forma eficiente en cuanto a requerimientos y resultados, al exigir pocos recursos y generar un gran valor agregado sobre los residuos manejados adecuadamente.

El proceso de fermentación homoláctica es un método de conservación de nutrientes, basado en la ausencia de oxígeno, con el fin de promover la fermentación de azucares a ácido láctico, lo cual causa un incremento de la acidez, inhibiendo la presencia de microorganismos que inducen la putrefacción (Wattiaux, 1999, citado por Ricse, 2013).

El presente trabajo de investigación pretende contribuir en mejorar el aprovechamiento del estiércol generado por los ovinos, así como también proponer una alternativa de manejo sanitario del mismo, evaluando la calidad de un abono orgánico líquido (biol) producido a partir del estiércol de los ovinos criados en los establos de la Universidad Nacional Agraria La Molina (UNALM), como parte del Programa de Ovinos y Camélidos Americanos (POCA), mediante dos procesos consecutivos: la digestión anaerobia en biodigestores (Biol I-G) y la fermentación homoláctica sobre el biol obtenido (Biol II-G).

Esta evaluación incluyó el monitoreo de los procesos de producción de los abonos orgánicos líquidos, en función a los tiempos y las características que estos requieran, analizar los parámetros físico-químicos, metales pesados y microbiológicos de los bioles producidos como resultado de las metodologías aplicadas e identificar los efectos fitotóxicos de la aplicación de los bioles en el proceso de germinación y el desarrollo de plántulas durante los primeros días de crecimiento en semillas de lechuga.

\section{Materiales y métodos}

El diseño experimental fue un Diseño Completamente al Azar (DCA) con dos tratamientos y tres repeticiones cada uno (Ver Figura 1). Los tratamientos evaluados fueron los siguientes:

(1) Tratamiento 1: Digestión anaeróbica en biodigestores para la producción de Biol I-G, llevado a cabo en el Laboratorio de Ingeniería Ambiental (LIA) de la UNALM durante los meses de agosto y diciembre del 2012. Las materias primas fueron estiércol de ovino, purín de cerdo y agua destilada.

(2) Tratamiento 2: Fermentación homoláctica en biodigestores para la producción de Biol II-G, llevado a cabo en el Laboratorio de Biorremediación de la UNALM durante los meses de enero y febrero del 2013. Las materias primas fueron Biol I-G, melaza y el consorcio microbiano generador de ácido láctico, denominado B-Lac.

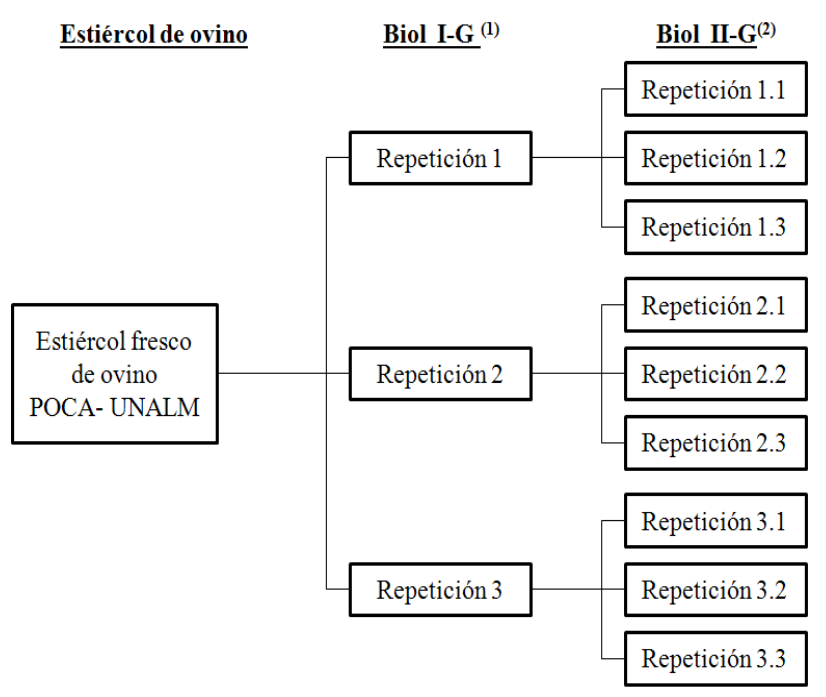

Figura 1. Repeticiones de cada tratamiento de la parte experimental.

Previo al inicio de la etapa experimental, se construyeron los 3 dispositivos (10 galones de capacidad) correspondientes al Tratamiento 1, los cuales fueron instalados bajo el diseño de biodigestor tipo batch que se presenta en la Figura 2.

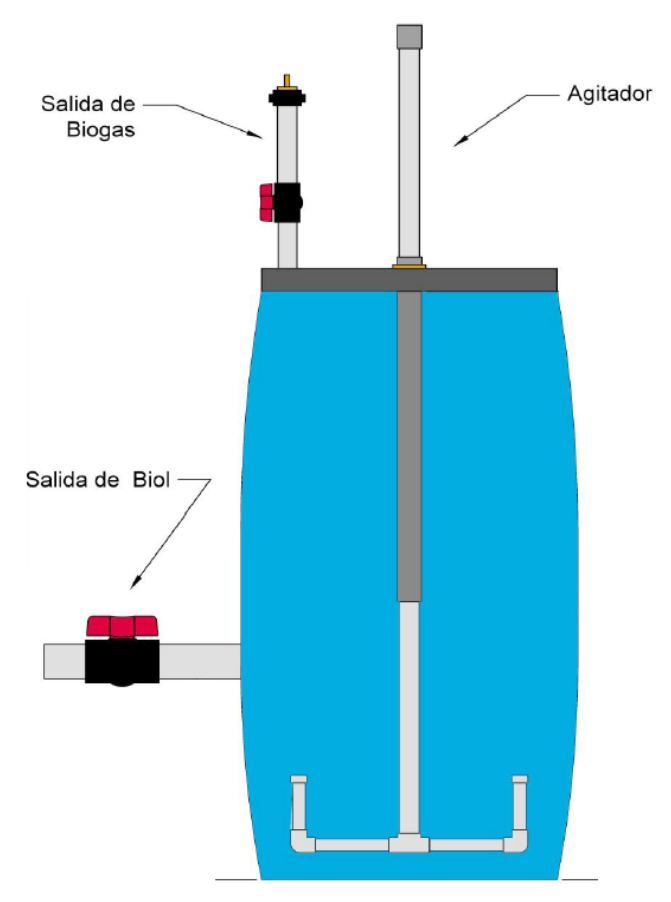

Figura 2. Diseño del biodigestor de Primera Generación (I-G). 
A la par, se realizó la caracterización inicial del estiércol de ovinos proveniente de los establos del Programa de Ovinos y Camélidos Americanos (POCA) en la UNALM, incluyendo los parámetros \%Humedad, \%C y $\% \mathrm{~N}$. A partir de estos valores en el volumen útil de 30.3 litros del biodigestor $(80 \%)$ se ingresó como carga única una mezcla constituida por $4.5 \mathrm{~kg}$ de estiércol de ovino, 4.5 litros de purín de cerdo ( $15 \%$ de la fase líquida del biodigestor) y agua destilada hasta enrasar el volumen de la fase líquida del biodigestor con una concentración de solidos de la mezcla del $8 \%$.

Una vez realizado el sellado de los reactores, se procedió a conectar los gasómetros a los reactores para que se pueda ir almacenando el biogás producido (ver Figura 3 ). El proceso de digestión anaeróbica tuvo una duración de 120 días, hasta que la concentración de metano en el biogás cayó luego de haber alcanzado su niveles máximos.

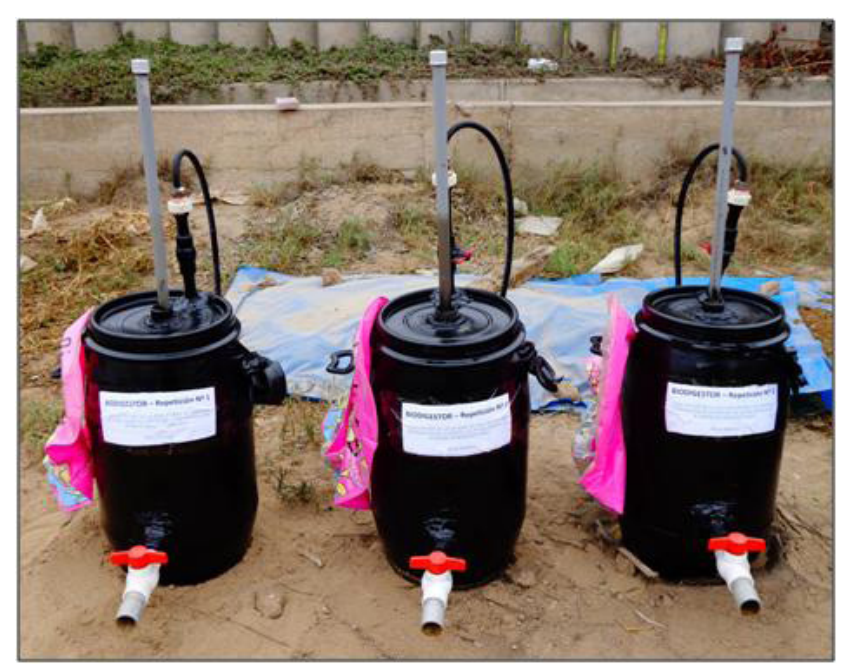

Figura 3. Instalación de tres biodigestores para el Tratamiento 1.

Durante el proceso de digestión anaeróbica se colectaron datos y se tomaron muestras de la fase líquida dos veces por semana, desde el primer día de instalación del Tratamiento 1, con el fin de medir los siguientes parámetros:

\section{pH}

La medición de $\mathrm{pH}$ se realizó a través del potenciómetro Hanna instruments HI8424, proporcionado por el Laboratorio de Ingeniería Ambiental. La medición se realizó dos veces por semana por espacio de quince días.

\section{Composición del biogás}

Para medir la composición del biogás se utilizó el equipo Monitor de Gas por Extracción, marca LANTEC, modelo GEM500, por el cual se detalla la composición porcentual de $\mathrm{CH}_{4}, \mathrm{CO}_{2}, \mathrm{O}_{2}$ y gases trazas en el biogás.
Las mediciones se realizaron dos veces por semana por espacio de diez semanas.

\section{Temperatura}

Mediante un sensor de temperatura que posee el mismo equipo Monitor de Gas por Extracción, marca LANTEC, modelo GEM500, se realizó la medición de la temperatura interna del sistema.

Una vez concluido el Tratamiento 1 que duró aproximadamente 120 días, se retiraron muestras de Biol I-G, las cuales fueron llevadas para análisis químico y de metales pesados en el Laboratorio de Análisis de Suelos, Plantas, Aguas y Fertilizantes (LASPAF) de la Facultad de Agronomía y análisis microbiológico en el Laboratorio de Ecología Microbiana y Biotecnología "Marino Tabusso" de la Facultad de Ciencias, ambos de la UNALM.

Como parte del análisis químico y de metales pesados, se incluyó el estudio de los siguientes parámetros: $\mathrm{pH}$, conductividad eléctrica, concentración de materia orgánica, nitrógeno, fósforo, potasio, calcio, magnesio, sodio, plomo, cadmio y plomo. Asimismo, en el análisis microbiológico se evaluaron los parámetros de enumeración de coliformes totales, coliformes fecales y Staphylococcus aureus y detección de Salmonella sp en 25 mililitros.

Para iniciar el Tratamiento 2, se instalaron 9 envases plásticos de 1.5 litros de capacidad con tapa hermética (Ver Figura 4). En estos se realizó una carga única de una mezcla constituida por Biol I-G (70\%), melaza como fuente de azúcares $(20 \%)$ y consorcio microbiano B-Lac $(10 \%)$ que propicia la fermentación homoláctica.

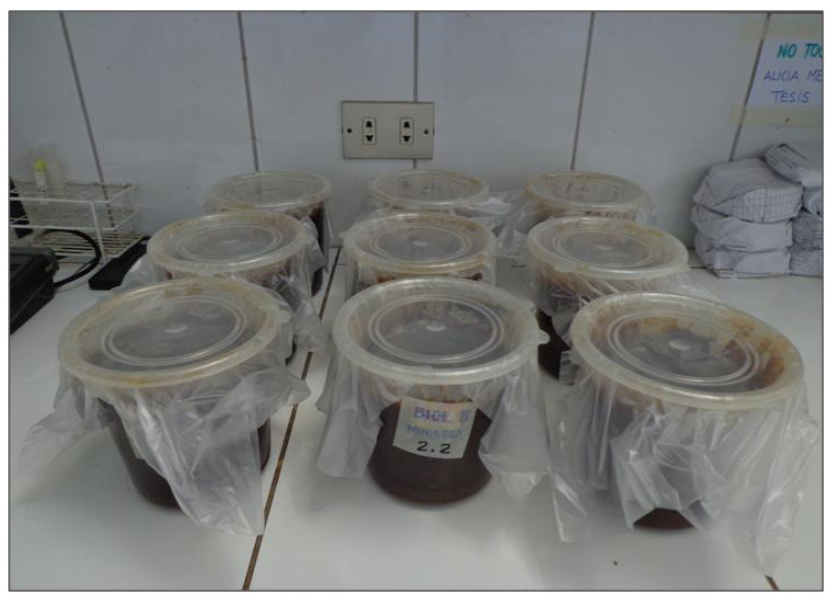

Figura 4. Instalación de nueve biodigestores para el Tratamiento 2 .

El proceso de producción del Biol II-G (Tratamiento 2) tuvo una duración de 5 días, ampliándose una etapa de análisis de estabilidad del producto por 30 dias. Durante los días de producción se tomaron datos diarios de $\mathrm{pH}$, porcentaje de ácido láctico y conductividad eléctrica, 
mientras que durante la etapa de análisis de estabilidad se evaluaron estos parámetros con una frecuencia de cada 5 días:

\section{pH}

La medición del pH se realizó a través del uso de potenciómetro Hanna HI8424.

\section{Porcentaje de ácido láctico}

Se determinó mediante la medición indirecta de ácido láctico titulable, siguiendo la metodología del titulado con hidróxido de sodio $0.1 \mathrm{~N}$ hasta encontrar el punto final correspondiente al cambio de $\mathrm{pH}$ del indicador fenolftaleína. El porcentaje de ácido láctico se calculó considerando el gasto en $\mathrm{mL}(\mathrm{G})$ y la normalidad (N) del $\mathrm{NaOH}$, el volumen de la muestra (m) y el miliequivalente del ácido láctico igual a 0.09:

$$
\begin{aligned}
& \% \text { Acidez titulable }=\underline{G * N * \operatorname{meq}_{\underline{\text { Ac. Láctico }}}} * 100 \\
& \text { m }
\end{aligned}
$$

\section{Conductividad Eléctrica}

Se efectuó por medición directa mediante el uso del conductímetro WTW 330i/SET.

Al término del Tratamiento 2, se retiraron muestras de Biol II-G, las cuales fueron llevadas para análisis fisicoquímico y de metales pesados en el laboratorio de Análisis de Suelos, Plantas, Aguas y Fertilizantes (LASPAF) de la Facultad de Agronomía y análisis microbiológico en el Laboratorio de Ecología Microbiana y Biotecnología "Marino Tabusso" de la UNALM. Los parámetros evaluados en dichos análisis de laboratorio son los mismos efectuados para el Biol I-G, con la finalidad de realizar una comparación entre ambos bioles.

Para la validación estadística de los datos se utilizó el programa Statical Analysis Software (SAS) versión 9.1, recurriendo al análisis de varianza (ANVA) y la prueba de Tukey, con un nivel de significancia del 5\% para ambas pruebas, con el propósito de determinar la significancia de todas las diferencias entre los bioles obtenidos a partir de cada tratamiento.

Por último, se estudiaron los efectos fitotóxicos de los bioles ejecutando el Ensayo de Toxicidad Aguda sobre semillas de lechuga (Lactuca sativa L.) variedad tipo Duett con cuyo poder germinativo es mayor al $90 \%$. Para ello, se establecieron 6 diluciones de evaluación, realizándose 3 repeticiones para cada una:

D0: Control Negativo o 100\% agua destilada

D1: Control Positivo o $100 \%$ biol puro

D2: Dilución del biol 10:100 (10\%)

D3: Dilución del biol 1:100 (1\%)

D4: Dilución del biol 0.1:100 (0.1\%)

D5: Dilución del biol 0.01:100 (0.01\%)
Se sembraron un total de 3660 semillas de lechuga tipo Duett, 20 semillas en cada placa Petri, exponiéndolas a 4 $\mathrm{ml}$ de la dilución de prueba.

Transcurrido el tiempo de evaluación (120 horas) se procedió a realizar el conteo de las semillas germinadas. Inmediatamente después, se midió la longitud de la radícula e hipocotilo de cada semilla germinada con ayuda de una regla milimetrada. Registrados dichos datos, se calculó el Índice de Germinación (IG) usando la siguiente fórmula:

$$
I G=\frac{P_{R G}^{*} C R R}{100}
$$

Donde:

PGR $=$ Porcentaje de Germinación Relativo:

$P R G=\underline{N^{\circ} \text { de Semillas germinadas en el extracto }} \times 100$ $N^{\circ}$ de Semillas germinadas en el testigo

$\mathrm{CRR}=$ Crecimiento de Radícula Relativo:

$$
C R R=\frac{\text { Elongación de radículas en el extracto }}{\text { Elongación de radículas en el testigo }} \times 100
$$

\section{Resultados y discusión}

\section{Monitoreo de los tratamientos}

El producto gaseoso de la digestión anaerobia de compuestos orgánicos, denominado biogás, contiene un alto porcentaje en metano $\left(\mathrm{CH}_{4}\right)$ de entre $50-70 \%$ (Martí, 2007). Sin embargo, dentro de la composición del biogás producido durante el Tratamiento 1 el porcentaje máximo de $\mathrm{CH}_{4}$ que se alcanzó fue de $34.5 \%$ en la repetición B1 y en promedio solo se lograron porcentajes de $30 \%$.

La composición del biogás depende de varios factores, pero esencialmente del sustrato a digerir, es así que la producción de metano que se obtuvo del estiércol de ovino dependió básicamente de su potencial como sustrato. Es por esta razón que suelen trabajarse procesos de codigestión, caracterizado por una digestión anaerobia conjunta de dos o más sustratos de diferente origen, con el fin de aprovechar la sinergia de la mezcla, compensando las carencias de cada uno de los sustratos por separado. En la Figura 5 se observa que la producción de metano se inició alrededor de la tercera semana de retención en todas las repeticiones, por lo que se debe tener en consideración que durante los primeros días, la actividad microbiana se concentra en la degradación de las moléculas orgánicas complejas. En el transcurso de las semanas, el $\mathrm{CH}_{4}$ se incrementó progresivamente y en los últimos registros se evidencia que el porcentaje de metano en el biogás producido disminuyó. Este descenso es causado por la falta de nueva materia orgánica como alimento para los microorganismos al finalizar el primer tratamiento ya que la alimentación has sido tipo batch. 


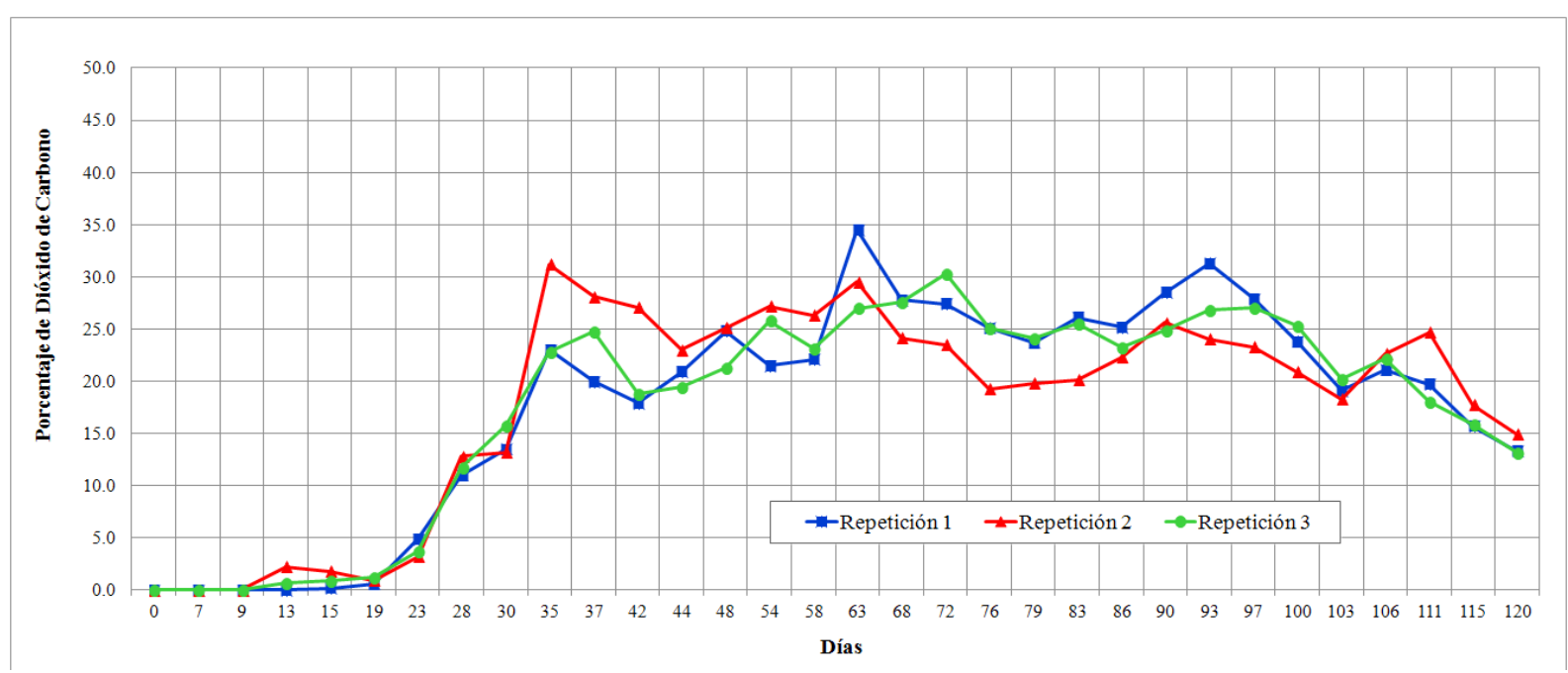

Figura 5. Variación del porcentaje de $\mathrm{CH}_{4}$ en el biogás producido.

Con respecto a la variación de temperatura interna del sistema, los valores fueron aumentando ligeramente a lo largo del proceso de biodigestión. El aumento es consecuencia de la variación de la temperatura ambiental (Castillo, 2010) por los cambios de estacionales. Asimismo, cabe mencionar que la temperatura interna asciende también porque la actividad microbiana se acentúa.
Al realizar la carga de las mezclas para el Tratamiento 1, estas presentaron un valor inicial promedio de $\mathrm{pH}$ igual a 7.56 .

Se monitoreó el parámetro $\mathrm{pH}$ en la fase líquida de los biodigestores registrándose estabilidad en este parámetro, según se presenta en la Figura 6.

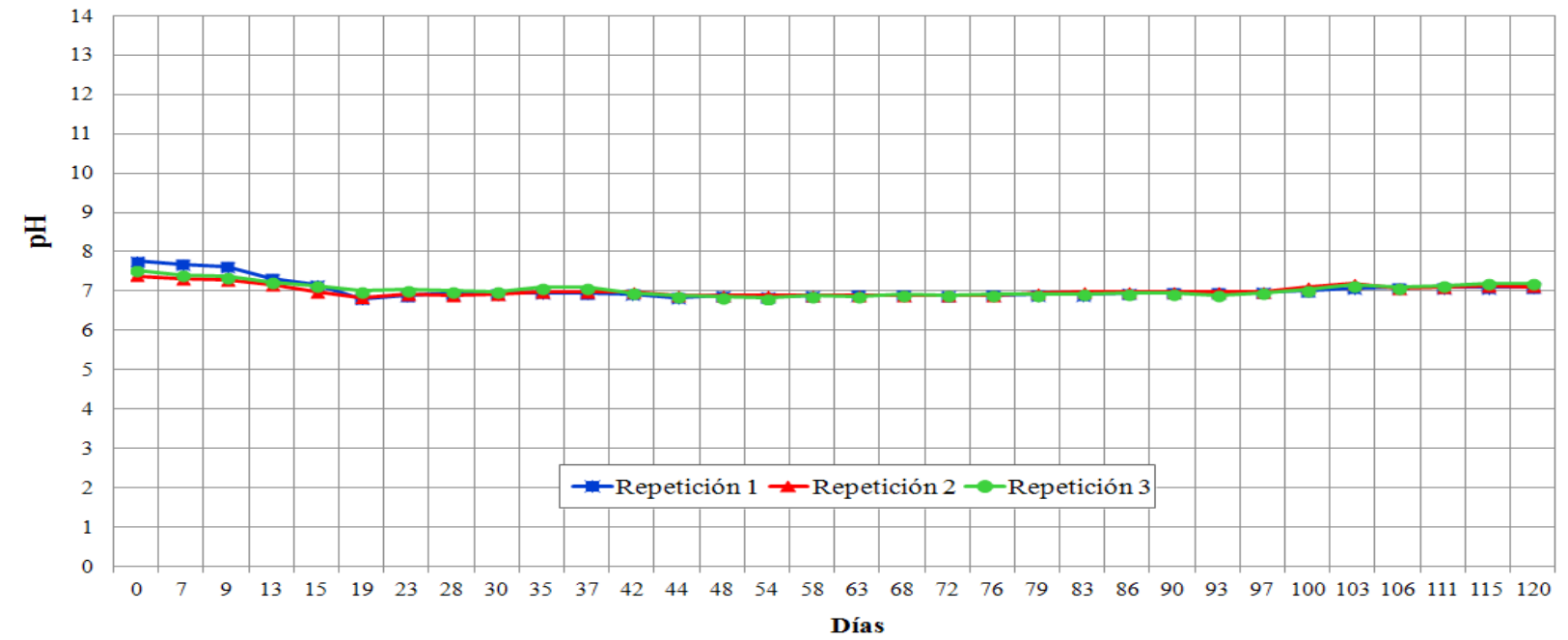

Figura 6. Variación del pH en la fase líquida de los biodigestores.

Debido a que el $\mathrm{pH}$ es un factor crítico para el normal desarrollo de la actividad de microorganismos presentes en la fase líquida, los valores deben mantenerse en un rango de entre 6 y 8 (Castillo, 2010). Como se puede observar en la Figura 6, los valores de $\mathrm{pH}$ se mantuvieron dentro de este rango óptimo durante todo el periodo de monitoreo. Esto debido principalmente a que el carácter del estiércol ovino, principal sustrato de la biodigestión, el cual no es ácido, sino más bien neutro.
Con respecto al proceso de producción del Biol II-G (Tratamiento 2), los valores iniciales de $\mathrm{pH}$, porcentaje de ácido láctico y conductividad eléctrica fueron $5.83,0.45 \%$ y $25.0 \mathrm{mS} / \mathrm{cm}$, respectivamente. Como se muestra en la Figura 7, durante los primeros cinco días, se observa que todas las repeticiones disminuyen su pH significativamente, alcanzando niveles ácidos de alrededor de 3.5. A partir de este $\mathrm{pH}$ se continuó la evaluación cada 5 días hasta los 30 días comprobándose que las condiciones de $\mathrm{pH}$ se mantuvieron y verificando su estabilidad. 


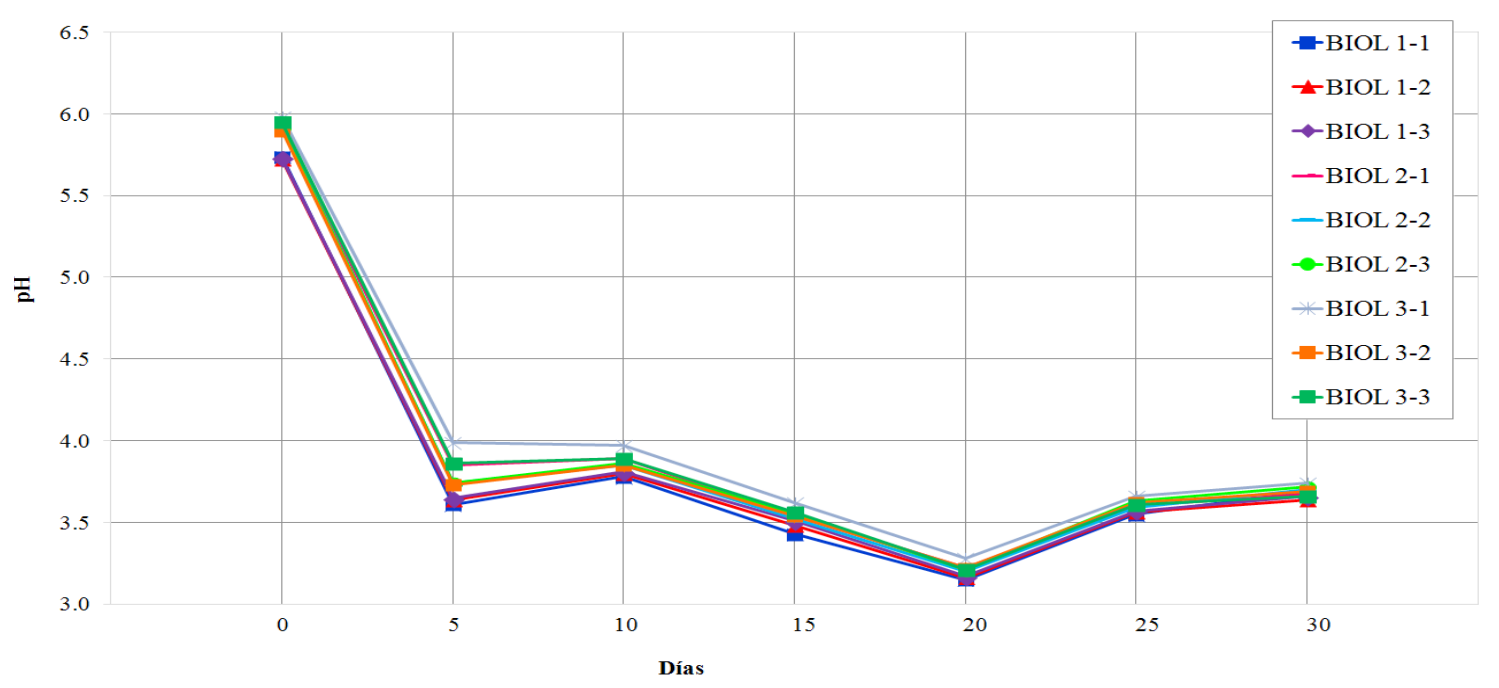

Figura 7. Variación del pH en el proceso de fermentación homoláctica.

Esta situación es producto de la acción de las bacterias ácido lácticas, las cuales realizan la fermentación de los carbohidratos hidrosolubles provenientes de la melaza, generándose ácido láctico y en consecuencia se aumenta la acidez en las mezclas (Peralta, 2010). El análisis del porcentaje de ácido láctico producido en las mezclas evidencia que efectivamente durante los primeros cinco días, la cantidad de ácido láctico aumenta considerablemente, alcanzando valores alrededor del 3\%. En los días siguientes esta generación de ácido láctico se estabiliza ya que la fuente de azúcar a lo largo de los días se ve agotada por las bacterias, además, según sostiene Aldón (2008), por el nivel de $\mathrm{pH}$ que se alcanza al quinto día, toda actividad microbiana, incluida la de las bacterias lácticas, se ve inhibida.

Las mediciones de la conductividad eléctrica nos muestran que a lo largo del proceso de fermentación homoláctica, se presenta una ligera variación de dicho parámetro manteniéndose siempre los valores entre 25 $35 \mathrm{dS} / \mathrm{m}$.

\section{Caracterización química}

Se determinó las características físico - químicas de cada repetición de los bioles de I-G (Tratamiento 1) y II-G (Tratamiento 2). Los resultados promedio para cada tratamiento se presentan en el Cuadro 1:

Cuadro 1. Resultados promedio del análisis fisicoquímico para cada tratamiento.

\begin{tabular}{|c|c|c|c|c|c|c|c|c|c|}
\hline Tratamiento & $\mathrm{pH}$ & M.O (g/L) & $\mathrm{C}(\mathrm{g} / \mathrm{L})$ & $\mathrm{N}(\mathrm{mg} / \mathrm{L})$ & $\mathrm{P}(\mathrm{mg} / \mathrm{L})$ & $\mathrm{K}(\mathrm{mg} / \mathrm{L})$ & $\mathrm{Ca}(\mathrm{mg} / \mathrm{L})$ & $\mathrm{Mg}(\mathrm{mg} / \mathrm{L})$ & $\mathrm{Na}(\mathrm{mg} / \mathrm{L})$ \\
\hline $\begin{array}{l}\text { Tratamiento } 1 \\
\text { (Biol I-G) }\end{array}$ & 7.23 & 3.1 & 1.8 & 321 & 55.4 & 1993 & 601 & 243 & 560 \\
\hline $\begin{array}{l}\text { Tratamiento } 2 \\
\text { (Biol II-G) }\end{array}$ & 3.66 & 108.6 & 63.0 & 1876 & 203.4 & 9006 & 1523 & 1044 & 591 \\
\hline $\begin{array}{l}\text { Biol Casa Blanca } \\
\text { (estiércol de cuy) }\end{array}$ & 8.20 & 5.4 & --- & 980 & 121 & 6760 & 220 & 53.4 & 542 \\
\hline $\begin{array}{l}\text { Biol La Calera } \\
\text { (gallinaza) }\end{array}$ & 7.20 & 17.2 & --- & 1700 & 3800 & 5200 & 3500 & 1200 & --- \\
\hline $\begin{array}{l}\text { Biol } \\
\text { Ciudad Saludable } \\
\text { (estiércol porcino) }\end{array}$ & 7.89 & 5.3 & --- & 1876 & 71.2 & 1940 & 105 & 27.6 & 3400 \\
\hline $\begin{array}{l}\text { FastBIOL } 20 \\
\text { (Estiércol vacuno) }\end{array}$ & 3.75 & 181.1 & --- & 4200 & 744.2 & 17200 & 5200 & 1740 & 1040 \\
\hline
\end{tabular}


El pH del Biol II-G es significativamente más ácido que el Biol I-G. Las concentraciones de materia orgánica revelan que el Biol II-G presenta una cantidad de materia orgánica mucho mayor a la de Biol I-G. Con respecto al contenido de nutrientes minerales, el Biol II-G presenta concentraciones más altas con referencia al Biol I-G. Según la prueba estadística de Tukey, las diferencias en las cantidades de nutrientes en el Biol I-G y el Biol II-G, excepto en el sodio, son altamente significativas $(\alpha<0.01)$. Esta manifestación es comprensible en el sentido de que a los nutrientes presentes en el Biol I-G se le agrega el aporte nutricional de la melaza, resultando después del proceso de fermentación, un producto (Biol II-G) enriquecido nutricionalmente. Se puede afirmar entonces que el Biol II-G es un abono orgánico líquido con mejores caracteristicas químicas que el Biol I-G. Al ser comparado con a otros bioles, producidos en similares condiciones y en base a otros estiércoles, se demuestra que sus condiciones son superiores en la mayoría de casos. Sin embargo, también se puede observar en el Cuadro 1 que el Fast BIOL 20 reune mejores condiciones nutricionales.

De igual manera, se determinó la concentración de metales pesados, plomo, cadmio y cromo, en la composición de los bioles I-G y II-G. Cabe mencionar que dichos elementos son de gran relevancia agronómica puesto que pueden potenciar el proceso de bioacumulación en la cadena trófica (Ricse, 2013). En el Cuadro 2 se presentan los resultados obtenidos:

Cuadro 2. Resultados de caracterización de metales, valores promedio $(\mathrm{mg} / \mathrm{L})$.

\begin{tabular}{cccc}
\hline Tratamiento & Plomo & Cadmio & Cromo \\
\hline $\begin{array}{c}\text { Tratamiento 1 } \\
\text { (Biol I-G) }\end{array}$ & 0.329 & 0.000 & 0.073 \\
$\begin{array}{c}\text { Tratamiento 2 } \\
\text { (Biol II-G) }\end{array}$ & 4.410 & 0.766 & 0.572 \\
\hline
\end{tabular}

Los contenidos de metales pesados en el Biol I-G son menores a los valores que presenta el Biol II-G. Al igual que en el caso de los nutrientes, esta diferencia muy marcada (ANOVA, $\alpha<0.01$ ) se atribuye a la incorporación de melaza, la cual contiene metales pesados en su composición.

Debido a que en el Perú no existe normativa que defina estándares referentes a concentraciones máximas permitidas de metales pesados en abonos orgánicos líquidos, los resultados obtenidos fueron llevados a concentraciones en base seca con el fin de ser comparados con normativa española referente a la utilización de lodos de depuración de aguas residuales en el sector agrario (Ver Cuadro 3).

Según se observa ambos bioles no superan ninguno de los estándares, pudiéndose catalogar incluso como un abono orgánico líquido de mucha calidad, con respecto a su contenido de metales pesados. Además, es importante precisar que el método de aplicación de los bioles es mediante dilución en el agua de riego, por lo que las cantidades de metales pesados adicionados al suelo serían bastante menores con respecto a las encontradas en el biol puro y, sobretodo a las que se vienen agregando a los suelos a través de fertilizantes químicos.

Cuadro 3. Valores límites de concentración de $\mathrm{Cd}, \mathrm{Cr}$ y $\mathrm{Pb}(\mathrm{mg} / \mathrm{kg})$.

\begin{tabular}{cccc}
\hline Tratamiento & Plomo & Cadmio & Cromo \\
\hline $\begin{array}{c}\text { Tratamiento 1 } \\
\text { (Biol I-G) } \\
\text { Tratamiento 2 } \\
\text { (Biol II-G) }\end{array}$ & 0.58 & 0.0 & 0.13 \\
$\begin{array}{c}\text { Lodo para uso agrícola, } \\
\text { suelo pH < 7* }\end{array}$ & 1000 & 20 & 750 \\
$\begin{array}{c}\text { Lodo para uso agrícola, } \\
\text { suelo pH > 7* }\end{array}$ & 1500 & 40 & 1200 \\
\hline *Norma Española Decreto Real 1310/1990. Regulación de la utilización \\
de lodos de depuración de aguas residuales en el sector agrario.
\end{tabular}

Los bioles también fueron sometidos a un análisis microbiológico, donde se evaluó: Coliformes Totales, Coliformes Fecales, Staphylococcus y Salmonella sp. puesto que la presencia de microorganismos patógenos en un abono orgánico implicaría riesgos a la salud de las personas, la calidad del suelo y de los cultivos. Los resultados presentados en el Cuadro 4 demuestran que a pesar que el estiércol fresco de ovino presenta valores de coliformes relativamente bajos en referencia a otros tipos de estiércoles (Castillo, 2010 y Peralta, 2010), esta presencia se inhibida de manera parcial en el Biol I-G, pero se elimina totalmente a nivel del Biol II-G; con una reducción de una unidad logarítmica después de completado cada proceso de producción.

Es importante destacar que el pH ácido del Biol II-G inhibe toda actividad de los microorganismos patógenos. Además, según Scobitz (2003) mencionado por Aldón (2008), las bacterias lácticas originan un grupo de antibióticos peptídicos con actividad bactericida que actúan en contra de las especies patógenas que puedan permanecer presentes durante el proceso de fermentación láctica, garantizando la inocuidad del producto.

Realizando una comparación entre los resultados obtenidos en el análisis microbiológico de los bioles y valores límites establecidos en la Ley General de Aguas de nuestro país, se encuentra que ambos productos cumplen con lo establecido.

Finalmente, siguiendo la metodología descrita por Sobrero y Ronco (2004), se dispusieron 5 diluciones para cada biol $(100 \%, 10 \%, 1 \%, 0.1 \%$ y $0.01 \%)$ sumadas a un control. Con relación a la germinación de las semillas, se logró el desarrollo normal de las semillas que en la mayoría de casos alcanzó un porcentaje de germinación mayor a 95\%, según se muestra en el Cuadro 6. No obstante, se pudo constatar que las semillas sembradas en las diluciones al $100 \%$ y $10 \%$ del Biol II-G no hubo germinación de ninguna de las semillas expuestas dado que presentan $\mathrm{pH}$ bajo y alta conductividad eléctrica y las semillas de lechuga son muy sensibles a estas condiciones. 
Las semillas germinadas en las diluciones $10 \%, 1 \%, 0.1 \%$ y $0.01 \%$ del Biol I-G alcanzaron medidas similares, e incluso superiores, a las que presentó el control. Esto es un indicador de la influencia positiva que tendrían estos bioles en la germinación y el desarrollo inicial de las plantas.

Por el contrario, en el caso del Biol II-G, la concentración $0.01 \%$ logró igualar la elongación alcanzada por el control. Por lo que se puede concluir que, mientras más diluido se encontró el Biol II-G, se alcanzaron medidas que evidenciaron una mayor influencia positiva como consecuencia de su aplicación. Tal como se muestra en el Cuadro 6 se presentan los valores Porcentaje de Germinación Relativo (PGR), Crecimiento de Radícula Relativo (CRR) y el Índice de Germinación (IG) para cada concentración de los bioles en las diluciones:

Según Varnero et al. (2007), los valores de $\mathrm{IG} \geq 80 \%$ indican que no hay sustancias fitotóxicas o están en muy baja concentración, por lo tanto hay un adecuado desarrollo de la germinación de la semillas y el crecimiento de la radícula. Sin embargo, este indicador para la presente investigación se refiere más bien a la identificación de concentraciones óptimas para el mejor desarrollo de las plántulas. Las diluciones de concentración $1 \%, 0.1 \%$ y $0.01 \%$ del Biol I-G presentan valores IG $\geq 80 \%$. Con respecto al Biol II$\mathrm{G}$, solo las disoluciones $0.1 \%$ y $0.01 \%$ alcanzaron un $\mathrm{IG}$ $>80 \%$. Las concentraciones más altas $(100 \%, 10 \%$ y 1\%) tuvieron una notable influencia negativa en los valores de Indice de Germinación, esto probablemente a la alta conductividad eléctrica y el $\mathrm{pH}$ muy bajo.

También afirma que un valor de $\mathrm{IG} \leq 50 \%$ indica que hay una fuerte presencia de sustancias fitotóxicas en la dilución por lo que en caso no se inhiba completamente la germinación de las semillas utilizadas, por lo menos se limitará el desarrollo de la radícula en estas.

Cuadro 4. Resultados de caracterización microbiológica, valores promedio.

\begin{tabular}{ccccc}
\hline Tratamiento & $\begin{array}{c}\text { Coliformes Totales } \\
(\mathrm{NMP} / \mathrm{mL})\end{array}$ & $\begin{array}{c}\text { Coliformes Fecales } \\
(\mathrm{NMP} / \mathrm{mL})\end{array}$ & $\begin{array}{c}\text { Staphylococcus } \\
(\mathrm{NMP} / \mathrm{mL})\end{array}$ & $\begin{array}{c}\text { Salmonella sp. } \\
(\mathrm{en} 25 \mathrm{~mL})\end{array}$ \\
\hline Estiércol fresco de ovino & $5.9 \times 10^{2}$ & $1.0 \times 10$ & $<3$ & Ausencia \\
Tratamiento 1 & (Biol I-G) & 4.0 & $<3$ & Ausencia \\
$\begin{array}{c}\text { Tratamiento } 2 \\
\text { (Biol II-G) }\end{array}$ & $1.5 \times 10$ & $<3$ & $<3$ & Ausencia \\
\hline
\end{tabular}

Nota: El valor $<3$ indica ausencia de microorganismo en el ensayo.

Cuadro 5. Valores límites de coliformes (NMP/mL).

\begin{tabular}{|c|c|c|}
\hline Tratamiento & Coliformes Totales (NMP/mL) & Coliformes Fecales (NMP/mL) \\
\hline $\begin{array}{l}\text { Tratamiento } 1 \\
\text { (Biol I-G) }\end{array}$ & $1.5 \times 10$ & 4.0 \\
\hline $\begin{array}{c}\text { Tratamiento } 2 \\
\text { (Biol II-G) }\end{array}$ & $<3$ & $<3$ \\
\hline Ley General de Aguas N ${ }^{\circ} 17752$ - Clase III & 50 & 10 \\
\hline
\end{tabular}

Cuadro 6. Índice de germinación (IG) de semillas de lechuga.

\begin{tabular}{ccccccc}
\hline \multicolumn{2}{c}{ Tratamiento } & $\begin{array}{c}\mathrm{N}^{\circ} \text { de Semillas } \\
\text { Germinadas }\end{array}$ & PGR $(\%)$ & $\begin{array}{c}\text { Elongación de la } \\
\text { Radícula }(\mathrm{mm})\end{array}$ & CRR (\%) & IG $(\%)$ \\
\hline Control (0\%) & & 20 & --- & 40.88 & --- & -- \\
& $100 \%$ & 19.4 & 97.2 & 9.91 & 24.23 & 23.56 \\
Tratamiento 1 & $10 \%$ & 19.9 & 99.5 & 39.24 & 95.98 & 95.50 \\
(Biol I-G) & $1 \%$ & 19.8 & 98.9 & 47.94 & 117.26 & 115.95 \\
& $0.1 \%$ & 20 & 100.0 & 41.20 & 100.77 & 100.77 \\
& $0.01 \%$ & 19.9 & 99.4 & 43.76 & 107.04 & 106.44 \\
\hline & $100 \%$ & 0 & 0 & 0 & 0 & 0 \\
Tratamiento 2 & $10 \%$ & 0 & 0 & 0 & 0 & 0 \\
(Biol II-G) & $1 \%$ & 19.8 & 98.9 & 27.73 & 67.28 & 67.07 \\
& $0.1 \%$ & 19.6 & 98.0 & 35.80 & 87.57 & 85.79 \\
\hline
\end{tabular}




\section{Conclusiones}

El estiércol de ovino es un residuo de las actividades agropecuarias con alto potencial de ser aprovechado como abono orgánico, al ser utilizado como materia prima en los procesos de biodigestión anaeróbica (Biol I-G) y de fermentación láctica (Biol II-G), procesos mediante los cuales se mejoran las concentraciones de sus nutrientes.

El proceso de producción del Biol I-G se caracteriza por un largo tiempo de retención (a nivel de meses) y una variación de $\mathrm{pH}$ entre los valores 6.8 - 7.8. Por lo contrario, el tiempo de retención para la producción del Biol II-G es de 5 días y la variación del pH es más amplia hasta alcanzar valores muy ácidos (alrededor de 3.5), los cuales se mantienen incluso después de haber transcurrido 30 días de iniciado el proceso.

Las concentraciones de nutrientes $(\mathrm{N}, \mathrm{P}, \mathrm{K}, \mathrm{Ca}, \mathrm{Mg}$ ) del Biol II-G son más altas que las que presenta el Biol I-G e incluso mayores que las de bioles generados a partir de otros residuos agropecuarios como la gallinaza, el estiércol de cuy y el estiércol de porcino. Con respecto a las concentraciones de metales pesados $(\mathrm{Cd}, \mathrm{Cr}$ y $\mathrm{Pb})$ en los bioles cumplen en general los límites máximos permitidos establecidos en las principales normativas instauradas a nivel mundial.

Los análisis microbiológicos realizados al Biol I-G evidencian que el proceso de biodigestión anaeróbica no eliminó con los patógenos presentes en el estiércol fresco de ovino. Así también, demuestran que el Biol II-G es un producto inocuo, que debido a su nivel de acidez está libre de microorganismos patógenos, y cuyo uso no implicaría riesgos a la salud de las personas, la calidad del suelo y de cultivos.

El ensayo de fitotoxicidad en semillas de lechuga demostró que el uso puro o en concentraciones muy altas de los bioles o bien inhiben la germinación de las semillas o de lo contrario limitan el crecimiento de la radícula en estas. Para el Biol I-G, se encontró que la dosis óptima es la dilución al 1\%; mientras que en el caso del Biol II-G, la dosis óptima está entre la dilución 0.1 y $0.01 \%$.

\section{Literartura citadad}

Aldón, D. 2008. Estrategia ambiental de aprovechamiento de la macroalga Ulva láctica a través del proceso de ensilaje. Tesis. Facultad de Ciencias. Universidad Nacional Agraria La Molina.

Castillo, G. 2012. Evaluación de codornaza y gallinaza de granjas avícolas para la producción de biogás y bioabono mediante digestión anaeróbica. Facultad de Ciencias. Universidad Nacional Agraria La Molina.

Martí, J. 2008. Biodigestores Familiares. Guía de diseño y manual de instalación. Biodigestores de polietileno tubular de bajo costo para trópico, valle y altiplano. GTZ Cooperación Técnica Alemana. Bolivia.
Peralta, R. 2010. Determinación de parámetros óptimos en la producción de fast biol usando excretas de ganado lechero del establo de la UNALM. Tesis. Facultad de Ciencias. Universidad Nacional Agraria La Molina.

Norma Española Decreto Real 1310/1990. Regulación de la utilización de lodos de depuración de aguas residuales en el sector agrario.

Ricse, Y. 2013. Elaboración de biofertilizante acelerado vía fermentación homoláctica del residuo de procesamiento de rocoto. Tesis. Facultad de Ciencias. Universidad Nacional Agraria La Molina.

Sobrero, M. y Ronco, A. 2004. Ensayo de Toxicidad Aguda con Semillas de Lechuga Lactuca Sativa L. Ensayos toxicológicos y métodos de evaluación de calidad de aguas. Estandarización, intercalibración, resultados y aplicaciones. IDRC, IMTA, Canadá.

Varnero, M., Rojas. y Orellana, R. 2007. Indices de fitotoxicidad en residuos orgánicos durante el compostaje. Universidad de Chile. Santiago de Chile. 10 p. 